\title{
Puertos y ciudades del Atlántico medio: análisis comparado entre Salvador de Bahía (Brasil) y Las Palmas de Gran Canaria (España)
}

\section{Ports and cities in Middle Atlantic: Salvador da Bahia (Brasil) \& Las Palmas de Gran Canaria, a comparative analysis}

\author{
Alejandro González Morales \\ Doctor en Geografía de la Universidad de La Laguna \\ Docente titular de la Universidad de Las Palmas Gran Canaria, España \\ https://orcid.org/0000-0002-2659-9678 \\ alejandro.gonzalez@ulpgc.es \\ Antonio A. Ramón Ojeda \\ Doctor en Geografía de la Universidad de Las Palmas Gran Canaria \\ Secretario de la Facultad de Geografía e Historia de la \\ Universidad de Las Palmas Gran Canaria, España \\ https://orcid.org/0000-0002-4578-5185 \\ toni.ramon@ulpgc.es \\ Flavio Gonçalves dos Santos \\ Doctor en Historia de la Universidad Federal Fluminense \\ Profesor titular de la Universidad Estatal de Santa Cruz, Brasil \\ https://orcid.org/0000-0003-4241-8870 \\ fgsantos@uesc.br
}

Fecha de recepción: 14 de febrero del 2018 Fecha de aceptación: 23 de marzo del 2018

Disponible en línea: 27 de junio del 2018

Sugerencia de citación: González Morales, A., Ramón Ojeda, A.A. y Gonçalves dos Santos, F. (2018). Puertos y ciudades del Atlántico medio: análisis comparado entre Salvador de Bahía (Brasil) y Las Palmas de Gran Canaria (España). tiempo\&economía, 5(2), 17-40 doi: http://dx.doi.org/10.21789/24222704.1335 


\section{RESUMEN}

Este artículo aborda un estudio diacrónico y comparativo entre dos ciudades atlánticas: Salvador de Bahía, Brasil, y Las Palmas de Gran Canaria, España, analizando su reciente transformación. Se estudia la evolución de ambas ciudades en relación con sus respectivos puertos y se establecen las concordancias y diferencias existentes en ambos procesos. El análisis comparativo aborda la geografía de cada ciudad, tanto como el origen y desarrollo portuario y urbano, para concluir que ambos espacios han seguido procesos similares de desarrollo, pero con etapas y casuísticas diferentes en cada caso.

Palabras clave: Puerto, ciudad, Salvador de Bahía, Las Palmas, transformación, historia económica

Códigos JEL: N90

\section{ABSTRACT}

This paper deals with a diachronic and comparative study between two Atlantic cities: Salvador da Bahia, Brazil, and Las Palmas de Gran Canaria, Spain, analysing their recent transformation. We study the evolution of both cities in relation to their respective ports and the concordance and differences existing in both processes. The comparative analysis addresses the geography of each city, as well as the origin and development of the port and urban areas. Although with logical differences, both spaces seem to have gone through similar processes of development, although the causes and results differ from case to case.

Keywords: Port, city, Salvador da Bahia, Las Palmas, transformation, economic history

JEL Codes: N90 


\section{Introducción}

El presente artículo tiene por objeto comparar dos espacios urbano-portuarios de dos oriIlas del Océano Atlántico: Salvador de Bahía en la costa noreste de Brasil, con una población de 2.675.656, según el censo de 2010 (estimada en 2.953.986 en 2017, según IBGE) y una superficie municipal de $706799 \mathrm{~km}^{2}$; y Las Palmas de Gran Canaria, espacio insular en la costa noreste del continente africano, con una población de 378.998 habitantes, en un municipio de $100 \mathrm{~km}^{2}$ (ISTAC, 2017) (figura 1).

Nuestra premisa de partida es que ambos espacios a pesar de ser muy dispares en extensión, población y condiciones naturales, tienen aspectos comunes asociados a su condición de ciudades portuarias. En este sentido, partiendo de un planteamiento diacrónico analizamos los desarrollos de los respectivos puertos en relación con las tramas urbanas conexas y cómo este proceso ha contribuido a conformar la realidad histórico-geográfica actual.

En ambos casos se ha producido un crecimiento de la ciudad en detrimento del recinto portuario, aun habiendo actuado éste inicialmente como dinamizador del crecimiento urbano. Ambos puertos experimentan una transformación de sus viejas estructuras dentro de un proceso que podemos calificar de "terciarización" y que afecta especialmente al espacio de confluencia del puerto con la ciudad. Esto supuso la necesidad de buscar nuevos emplazamientos para las infraestructuras portuarias, pero también posibilitó que esos espacios liberados fueran ocupados por la ciudad con nuevas funciones para los mismos. Se produce pues un cambio sustancial de usos que hacen del puerto una realidad geográfica mucho más integrada en la trama urbana.

Figura 1. Mapa de localización de Salvador de Bahía y Las Palmas de Gran Canaria

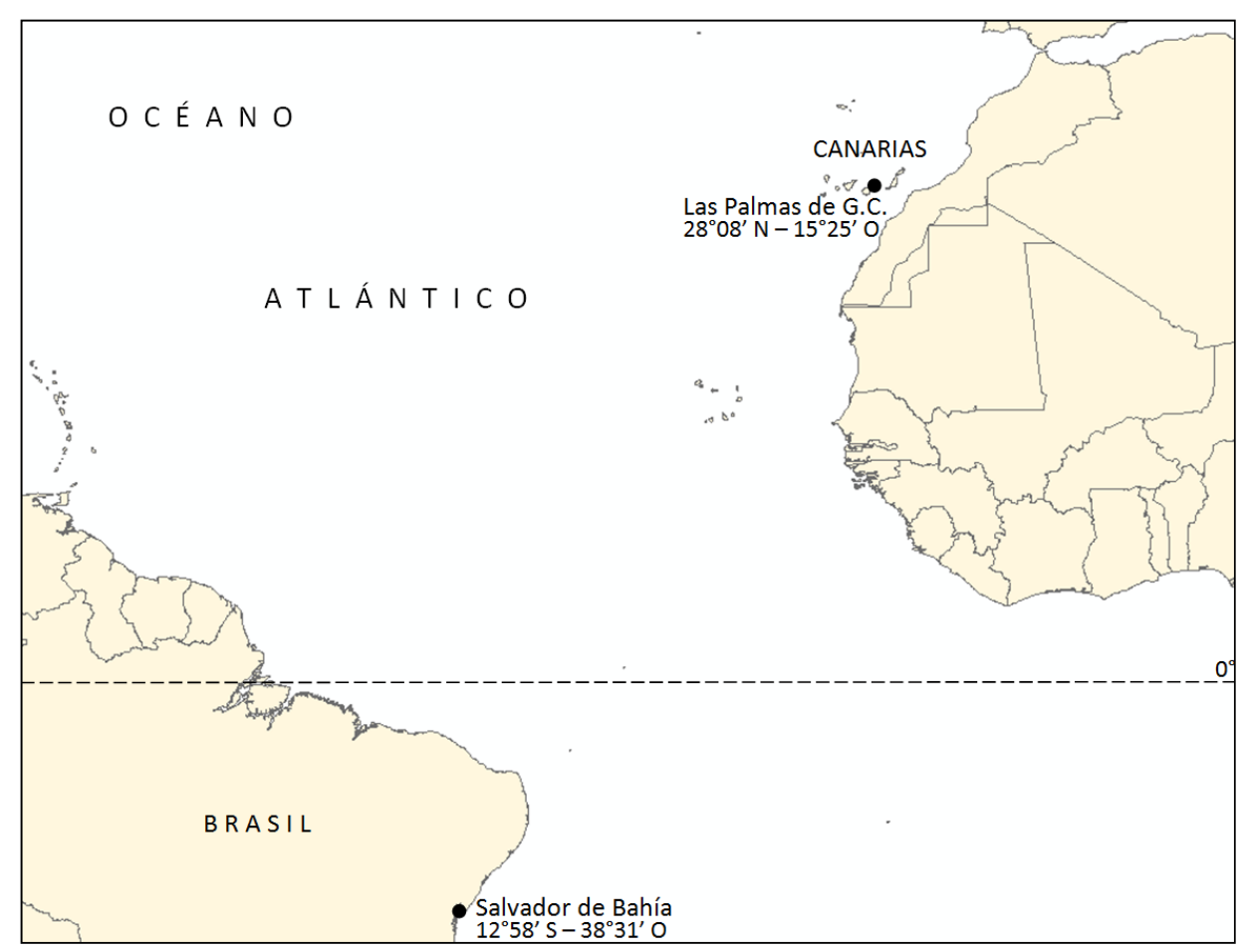

tiempo\&economía

Vol. 5 N. 2 - Julio - Diciembre del 2018 
Podemos afirmar que en ambos casos se ha producido un proceso similar de terciarización y urbanización creciente, de deslocalización y traslado de las actividades industriales y logísticas, aunque lógicamente con fases o etapas distintas y con resultados diferentes.

En el caso brasileño la industrialización ha sido la principal causa de los cambios recientes, hasta el punto que ha obligado a construir un nuevo puerto lejos del histórico de Salvador de Bahía (Aratu, $20 \mathrm{~km}$ al norte). El desarrollo inicial del viejo puerto se debió principalmente a la producción de caña de azúcar y el comercio de esclavos, dinámica que se mantuvo hasta el siglo xIx. En 1869 se aprobó el Decreto Imperial que supone un espaldarazo importante al desarrollo moderno del puerto de Salvador de Bahía, si bien hay que esperar a 1923 para observar las primeras grandes inversiones que supondrán la transformación y modernización de los muelles, tinglados, almacenes e infraestructuras portuarias (Santos, 2013). Por último, fue a partir de la década de 1960 con la instalación de la industria petroquímica (Petrobras), que se trasladó la infraestructura hacia el interior de la bahía y se impulsó el nuevo puerto industrial junto a la base naval de Aratu, conectado a Salvador de Bahía mediante una dinámica autopista.

En cuanto a Las Palmas (cuyo nombre oficial es Las Palmas de Gran Canaria), la ciudad también se desarrolló por la industria de la caña de azúcar, pero al contrario que en Salvador, el comercio de esclavos tuvo poca importancia. Además, ninguna de estas actividades justificaron inversiones en infraestructuras portuarias, pues estas se emprendieron a finales del siglo XVIII, cuando hacía mucho habían desaparecido los cañaverales (Lobo, 1993) y la actividad se centraba en el comercio con América y Europa.

El muelle Las Palmas, el primero que tuvo la ciudad, se construyó a finales del siglo xvIII junto al barrio histórico de Triana. Sin embargo, fue una obra mal planificada e inoperativa, especialmente con temporales del sur. Por este motivo, en 1883 se inician las obras de los nuevos muelles de La Luz y de Santa Catalina, emplazados en esta ocasión en la zona abrigada de la Bahía de La Isleta, $5 \mathrm{~km}$ al norte de los barrios históricos. El puerto creció y con él la ciudad, generando un espacio tensionado en el que esta última acabó imponiéndose ocupando progresivamente antiguas y obsoletas zonas portuarias -desde 1970-, desplazando así al puerto hacia el noreste, o lo que es lo mismo, hacia La Isleta y la Península del Nido. Se construyeron allí los diques Reina Sofía y Nelson Mandela que conforman la dársena exterior del actual puerto, completamente separada de la ciudad (González y Ramón, 2017). Tras este crecimiento portuario el espacio de unión entre la ciudad y el puerto se fue transformando, resultado de un proceso de terciarización que también observamos en Salvador de Bahía.

Por tanto y como se podrá comprobar, existen similitudes en la configuración de ambos puertos y también de sus espacios urbanos anexos. En ambos casos existe una Ciudad Baja (Cidade Baixa), que entra en contacto con el puerto, y una Ciudad Alta (Cidade Alta) que resulta de la expansión urbana al colonizar los relieves próximos al mar. El desarrollo sigue etapas similares, pero con periodización diferente. Igualmente en ambas ciudades se han dado procesos similares de planificación y distribución de usos, de manera que las actividades más molestas y difícilmente integrables en la trama urbana han sido desplazadas a emplazamientos alejados de la ciudad, Aratu en el caso brasileño, y las dársenas exteriores de los diques Reina Sofía y Nelson Mandela, en el caso canario. Por otra parte, este proceso obedece a una planificación integral de las infraestructuras portuarias, donde la presencia urbana acaba por 
imponerse e incluso arrebatarle al puerto terrenos que son transformados en un espacio para la ciudadanía. (González y Ramón, 2016). En el entorno de estos nuevos espacios portuarios se están reproduciendo las mayores infraestructuras urbanas que ligan al puerto y la ciudad (en el caso de Las Palmas de Gran Canaria: el acuario, el centro comercial El Muelle, el intercambiador de transporte y la zona de ocio del entorno del parque Santa Catalina); mientras que en el entorno del puerto de cruceros brasileño se establece una zona de ocio y turismo en el entorno del Pelourinho y el Mercado Modelo -en el predio de la antigua Aduana-, una marina, restaurantes, aparcamientos y espacios de festivales y festejos en las zonas de los antiguos almacenes.

\section{Metodología}

El presente estudio tiene tanto una perspectiva geográfica como una orientación histórica, y analiza de manera diacrónica y comparada procesos similares en relación con el espacio urbano-portuario de las ciudades de Salvador de Bahía y Las Palmas de Gran Canaria.

Se incorpora además una visión urbanística donde entra el análisis descriptivo del origen y desarrollo de los puertos y su influencia recíproca con las respectivas tramas urbanas. Dentro de la abundante bibliografía de estudios que abordan esta temática, existe una línea de trabajo específicamente orientada a analizar las relaciones entre el puerto y la ciudad (Hayuth, 1989; Hoyle, 1994; Gómez y Grindlay, 1998; Casariego et al., 1999; Rowe et al., 2001; Martín, 2001, etc.), donde con frecuencia se analizan los usos y funciones de ambas realidades geográficas y su espacio de confluencia, incluso la incidencia ambiental de dicha relación y los procesos de cambio. También comienza a ser cada vez más frecuente hallar estudios que abordan el "terciario portuario" (Delgado, 1998; Delgado et al., 2007), dentro de un proceso que nosotros hemos preferido denominar "de terciarización".

El hecho significativo es que la relación entre el puerto y la ciudad ha ido evolucionando con el paso del tiempo, de ahí la justificación de un análisis diacrónico. También es notorio que el diálogo entre ambas realidades ha estado circunscrito, por una parte a los objetivos e intereses principales de cada uno; y por otra, a una evolución en la forma de entender la planificación, de manera que de una etapa inicial en la que primaba esencialmente el carácter comercial, logístico y de movilidad propio de las infraestructuras portuarias, se ha pasado a una etapa más reciente en la que el puerto es concebido -léase, planificado- con una mayor integración respecto a su entorno, donde destacan las actividades terciarias.

Estas premisas constituyen las hipótesis de trabajo del presente estudio. Con el fin de realizar el citado análisis se ha procedido a recrear la evolución y el crecimiento de las obras del puerto, así como la expansión de la ciudad, a partir de la documentación a la que hemos tenido acceso. Para ello se ha recurrido a fuentes básicas como son el archivo de la Autoridad Portuaria de Las Palmas, la Oficina de Planeamiento del Ayuntamiento de Las Palmas de Gran Canaria, Museo Canario, fondo cartográfico y fotografías aéreas del Departamento de Geografía de la ULPGC, fondo fotográfico de la Fedac y Archivo Histórico Provincial de Las Palmas. En la documentación referente al caso brasileño destacan el fondo documental del Arquivo Público do Estado de Bahia; la Biblioteca Pública del mencionado Estado; el Arquivo do Ministerio da Fazenda en Rio de Janeiro y el Centro de Documentação Informação da Companhia de Docas do Estado da Bahia. Nos apoyamos en documentación cartográfica y fotográfica, 
complementada también con documentos de planeamiento, correspondencia oficial, y documentos de expedientes de tramitación de mercancías.

También resultan de interés para conocimiento del proceso general de desarrollo del puerto y la ciudad publicaciones de investigadores como Martín (2001, 2007), Rosado (1983), Herrera (1984, 2008); Cáceres (2011); Casariego y Guerra (1999) y Moreno (2015), quienes estudian ambas ciudades desde una perspectiva histórica. Además, también se han empleado imágenes del Mando Aéreo de Canarias, publicadas por Medina (1996), que nos han resultado muy útiles para analizar el proceso conjunto de transformación del litoral, el puerto y la ciudad, así como la recopilación cartográfica de la obra de Tous Melián (Melián y Herrera, 1995), donde encontramos mapas históricos que ilustran los cambios acontecidos en la ciudad.

Finalmente, se han puesto en relación ambos casos estudiados con el fin de establecer similitudes y diferencias en lo que entendemos como un proceso general concordante pero no coetáneo.

\section{El medio Natural de Salvador de Bahía y de Las Palmas de Gran Canaria}

El emplazamiento geográfico de ambos ámbitos de estudios, así como las características de sus respectivos litorales, son diferentes entre sí. Salvador de Bahía se ubica en la desembocadura del estuario de los ríos Paraguaçu y Jacuípe, en la Baía de Todos os Santos, de donde adopta su nombre; mientras que Las Palmas de Gran Canaria lo hace al norte de la isla de Gran Canaria, junto a la Bahía de la Luz, en un litoral abierto al este, pero parcialmente abrigado por la presencia de La Isleta.

El litoral de Salvador corresponde a una litología calcárea que da lugar a una morfología predominantemente llana, donde las playas y manglares son la nota dominante. Desde la Barra, al sur de la extensa lengua de tierra donde se asienta la ciudad y el puerto viejo, hasta el nuevo puerto industrial, y también base naval, de Aratu, $20 \mathrm{~km}$ al norte, encontramos una costa quebrada, con penínsulas y ensenadas que se abren hacia el noroeste. Los relieves son bajos (no más de $70 \mathrm{~m}$ ), apenas promontorios de escasa altitud que se disponen en sentido noreste-suroeste paralelos a la costa. En la zona vieja de la ciudad (Praça Municipal, Praça da Sé, Pelourinho y Comercio), donde se encuentra el antiguo puerto, la plataforma litoral es estrecha y el terreno asciende rápidamente hasta los 60-70 metros de altitud (Cidade Alta), limitando por tanto el crecimiento y expansión del puerto hacia naciente. Desde el punto de vista fisiográfico, de sur a norte podemos diferenciar las siguientes unidades:

1. Playas y manglares con escasas obras portuarias (sólo algunos pantalanes privados) entre Farol da Barra, en el extremo sur, hasta el muelle deportivo de Baía Marina.

2. Espacio portuario y por tanto litoral antropizado, que se extiende hasta la playa de Calçada, inicio de la península de Ribeira.

3. Península de Ribeira, Baía de Itapajipe y promontorio de Plataforma y Periperi, donde alternan las playas de arenas organógenas (Ribeira), tramos de costa de manglares y zonas urbanas (Itapajipe) y la combinación de ambos, esto es, manglares, playas y espacios residenciales (Plataforma y Periperi). 
4. Península y Baía de Aratu, donde en costas opuestas y muy próximas se despliega la base naval y el puerto de Aratu, alternando con tramos de costa natural y escasa urbanización fuera del ámbito portuario.

En el caso del puerto canario y su ciudad, el litoral es volcánico y se encuentra orientado a naciente, y no a poniente como el de Salvador de Bahía. La ciudad se extiende paralela a la costa a lo largo de casi 9 kilómetros, donde podemos distinguir las siguientes zonas:

1. La Isleta, que se caracteriza por su costa irregular, en algunos tramos de acantilado bajo y muy quebrada con numerosos salientes y rompientes. Completamente transformada por obras portuarias y espacios urbanos.

2. La zona intermedia la ocupa un tómbolo (istmo de Guanarteme, entre las playas de Alcaravaneras y Las Canteras), resultando por tanto una costa baja y arenosa, aunque contaba con algunos salientes lávicos y arrecifes rocosos, todo lo cual ha desaparecido bajo la ciudad, la base naval y el muelle Santa Catalina. Sólo permanece la Playa de las Alcaravaneras y Las Canteras (antes Ilamada del Arrecife).

3. Al sur se encuentra la plataforma litoral, donde originariamente se fundó y desarrolló la ciudad vieja (casco histórico) y el primer muelle (muelle de Las Palmas, hoy desaparecido). Como en el caso de Salvador de Bahía, también aquí la ciudad se encuentra abrigada hacia el lado de tierra por un relieve paralelo a la costa y de una altitud media que ronda los 80 metros. Todo este litoral ha quedado sepultado por el puerto y la Avenida Marítima (González y Ramón, 2017).

\section{Los procesos de cambio en el puerto y la ciudad}

\section{Los procesos de cambio en el puerto de Salvador de Bahía y Aratu}

La génesis de lo que hoy podemos llamar sistema portuario bahiano se materializó bajo la hegemonía del Puerto de Salvador, que a su vez surgió y se estructuró bajo la égida de la explotación colonial y del monocultivo esclavista a lo largo de los siglos XVI al XIX. Durante ese periodo puerto y ciudad mantuvieron una "estrecha relación espacial y funcional", algo característico, según Hoyle (1997) de aquellos puertos naturales situados en bahías abrigadas donde desemboca algún río.

Salvador fue el principal puerto brasileño hasta el siglo xvill, cuando la capital se trasladó a Río de Janeiro, alzándose este último con la primacía de los tráficos portuarios del país (Lapa, 1968; Honorato, 1983). A pesar de ello el puerto bahiano mantuvo un intenso movimiento comercial, impulsado sobre todo por el tráfico negrero, hasta mediados del siglo XIX, cuando comienza su declive en el contexto nacional tras la segunda revolución industrial (Santos, 2013). 
Figura 2. Zona Portuaria de Salvador, según Carlos Weyll (1851)

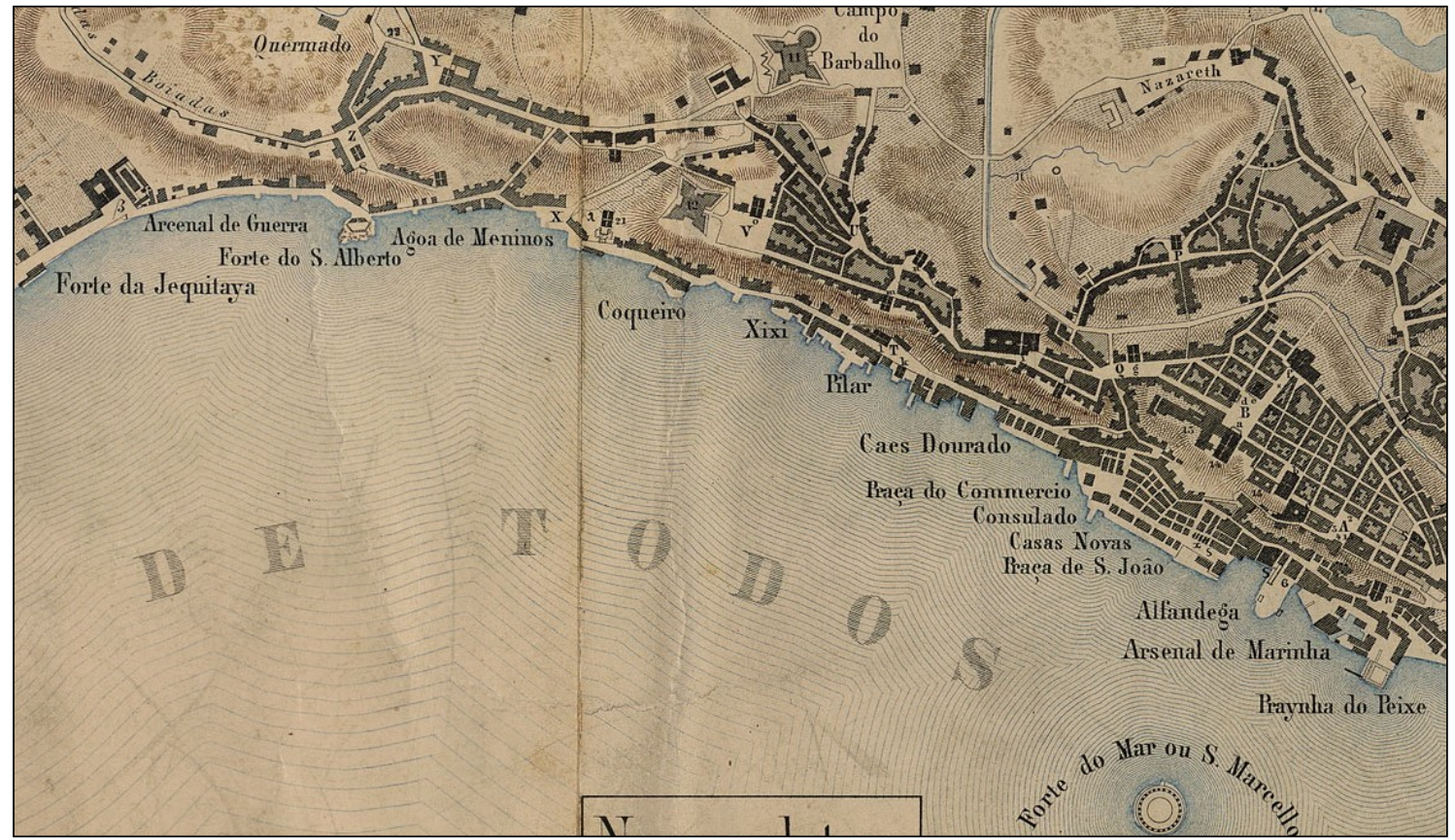

Fuente: Mapa Toppgraphica da Cidade de S. Salvador e seus subúrbios, por Carlos Augusto Weyll, publicada por Ferb. Gloker, impressa em Stuttgart por Fr. Malté. Acervo Cartográfico da Biblioteca Nacional do Brasil

La zona portuaria de Salvador, alrededor de 1851 (figura 2), estaba comprimida en una estrecha franja de tierra, que se extendía desde el Arsenal de la Marina hasta Agua de Meninos. En esta región se concentraba buena parte de los sectores responsables del abastecimiento de la ciudad, como las casas comerciales, con sus "trapiches". (almacenes), así como algunas administraciones públicas (Aduana e Inspección Sanitaria, entre otras) (Honorato y Mantuano, 2015). Esta zona dispuso de abundante fuerza de trabajo gracias a los esclavos y a los libertos. Se trata de un espacio de pequeños comercios y de servicios, y constituyó el auténtico motor y corazón de la ciudad. En otras palabras, el puerto fue el que permitió el desarrollo urbano, social y económico de Salvador de Bahía.

La plaza comercial de Salvador, hasta principios del siglo xx, apenas experimenta cambios, y continúa siendo principalmente una zona comercial portuaria. El puerto de Salvador hasta finales del siglo xIx presentaba 35 trapiches y almacenes, asociados a once muelles o cais (Rosado, 1983).

Según Moreno (2015, p. 125), "comerciantes, trampistas, agricultores y otros que representaban el gran capital bahiano fueron los pioneros en la fundación de la Associação Comercial da Bahia". Esta asociación será el germen del desarrollo comercial y, a pesar de que en sus estatutos se prohíbe la participación política directa, se constituirán en una fuerza política de primer orden, siendo decisivos en el desarrollo del puerto y de la ciudad.

En 1869, con la Ley de Modernización de los Puertos, los segmentos económicos soteropolitanos $^{1}$ impulsaron importantes mejoras en las infraestructuras y en el calado del puerto.

1 Gentilicio para los naturales de Salvador de Bahía. 
Entre 1854 y 1923 el "carácter fragmentado de la zona portuaria, que pertenecía tanto a particulares y al Estado" desencadena una serie de conflictos que paralizan las inversiones (Rosado, 1983, p. 36).

Las obras de modernización se iniciaron en el año 1906, después de un largo periodo de espera. Según la cronología de Rosado, la primera etapa comenzó con las reivindicaciones de 1854 y terminó en 1891 cuando la Companhia Docas e Melhoramentos da Bahia coloca las amarras en el puerto.

La segunda fase, que se inició en 1891, fue también de escaso crecimiento y estuvo propiciada por los frecuentes aplazamientos que retrasaron las obras de modernización hasta 1906. Se tardó unos siete años en inaugurar los primeros almacenes y los primeros 360 metros de muelle. La última etapa concluyó en 1922 con la terminación de estas obras de mejora (Rosado, 1983, 2000).

La planificación de la ciudad siguió los patrones de la Comuna de París, en el sentido que se intentó reducir las zonas socialmente peligrosas en el entorno portuario. ${ }^{2}$ La ciudad comenzó a crecer con criterios capitalistas y de mentalidad burguesa a partir del siglo xx.

La primera gran intervención se inició precisamente en la zona portuaria, con el relleno de un área de más de 5 kilómetros de extensión, de los cuáles aproximadamente 800 metros son de terreno ganado al mar, los que van desde la actual plaza Visconde de Cairu hasta el Jequitaia (actual barrio de la Calzada) (figura 3). El relleno se aprobó con el Decreto 4695 de 15 de febrero de 1871, que significó la primera concesión para la realización de las obras de mejora del puerto de Salvador.

Fueron muchos los retrasos y la normatividad que afectaron las obras de mejora del Puerto de Salvador, así como los concesionarios que las asumieron, sin que finalmente pudieran llevarse a cabo por las razones ya esgrimidas. Por fin, el 6 de junio de 1905 (Decreto 5.550), se renueva el contrato de la Compañía Internacional de Docas y Mejoramientos de Brasil y las obras comenzarían al año siguiente.

En 1913, año de su inauguración oficial, el Puerto de Salvador ya estaba en plena actividad y la renta que generaba inició un proceso de crecimiento constante. Sin embargo, las obras aún no estaban plenamente concluidas, aunque a finales de 1920 las características de la zona portuaria de Salvador ya eran completamente distintas en relación al puerto de 1850 y los cambios manifiestos con respecto al siglo xIX.

Paralelamente a este crecimiento, la ciudad fue ocupando las áreas creadas por el puerto, lo que a su vez propicia la creación de nuevos cais y zonas de infraestructuras portuarias. Se establecen en esta zona de la Ciudad Baja: bancos, casas comerciales y organismos públicos, como la Agencia Central de Correos, el Cuartel de Infantería de Marina y el Instituto del Cacao. Asimismo, también aumentaron las vías de circulación para el creciente flujo de automóviles desde y hacia el puerto. Con el aumento del flujo de automóviles y la incorporación de autobuses al servicio de transporte público colectivo, la Avenida de Francia se convirtió en una importante vía de comunicación y de estructuración y vertebración de la ciudad.

2 En el caso de Salvador, por clases peligrosas se entendían además de los pobres, desocupados y excluidos sociales, los esclavos y ex-esclavos, ya que el país se encontraba en el umbral de la abolición definitiva de la esclavitud legal a finales del XIX.

tiempo\&economía

Vol. 5 N. 2 - Julio - Diciembre del 2018

p. 25 
Figura 3. Evolución de la zona portuaria de Salvador de Bahía

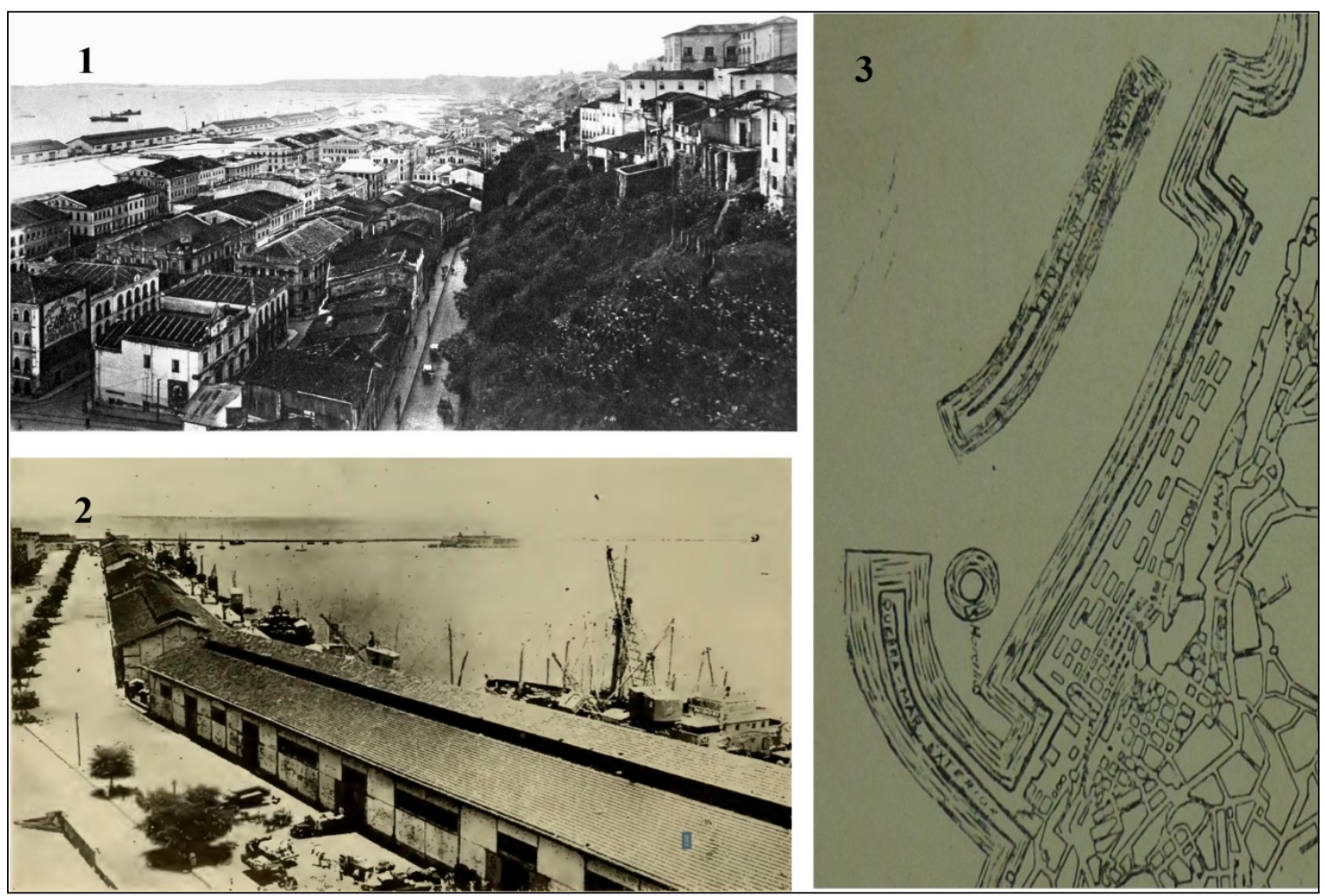

Pie de fotos: (1) Vista panorámica de la Cidade Baixa, donde destacan los terrenos ganados al mar en 1917 -

Fuente: Colección da BPEB; (2) Zona portuaria de Salvador en 1928. (Sampaio, 1928): Indicador e Guía Prático da Cidade de Salvador. Tipografia Barbosa \& Cia. Salvador; (3) Aspecto parcial del Cais del puerto de Salvador en 1940 (Revista Fiscal da Bahia, 1949: XX).

El proceso de urbanización continuó durante el siglo xx ocupando e integrando a la red urbana las regiones más alejadas del litoral, incluyendo la Ciudad Alta, de modo que la urbe crecía sin ocupar la zona portuaria. Se desarrollaron de forma paralela espacio portuario y urbano sin restarse protagonismo, pues las disponibilidades de terreno lo permitían.

Después del final de la Segunda Guerra Mundial (1945), se tomaron numerosas medidas para mejorar las condiciones de operatividad del puerto soteropolitano, con el fin de adecuar las infraestructuras a las nuevas exigencias que el escenario posguerra imponía. En esta época se intensificaron los conflictos entre el espacio portuario y su área urbana próxima debido al aumento del parque automovilístico y también de los vehículos de tracción animal. Los primeros fueron ganando cada vez más importancia sobre los segundos. Este proceso propició que la categoría de tracción animal acabara desapareciendo entre 1950 y 1970 (Santos, 2015).

La economía de Bahía a mediados del siglo xx seguía dependiendo de los productos agrícolas. Sin embargo, el inicio de la explotación de petróleo en la Baía de Todos os Santos, en 1939, y la construcción de la refinería de Petróleo de Mataripe, en la Región Metropolitana de Salvador, en 1949, impulsó una potente industrialización auspiciada desde el Estado con capitales públicos. La construcción del Centro Industrial de Aratu, en 1967 y los estudios para la implantación del primer Polo Petroquímico de Bahía, marcaron el inicio de la construcción del Puerto de Aratu, ubicado en la ensenada del Caboto. 
El nuevo puerto también fue impulsado por un proyecto nacional desarrollista para dar soporte y cobertura al complejo industrial que se estableció en la región metropolitana de Salvador. Pensado inicialmente como un puerto privado de la Siderúrgica de Bahía, su proyecto evoluciona en el sentido de atender tanto al Centro Industrial de Aratu, como posteriormente al Polo Petroquímico de Bahía, que se instaló en la región de los municipios de Camaçari y Dias d'Ávila.

De modo distinto al caso canario, la asignación de actividades industriales y de movimiento de vehículos con cargas pesadas o con mercancías insalubres, que tenía como destino u origen el puerto, fueron desplazadas a otras áreas en la región metropolitana de Salvador de Bahía. En la tabla 1 es posible percibir que el Puerto de Aratu a partir de la década de 1980 asume el liderazgo en el movimiento de embarcaciones y volumen de cargas en relación al Puerto de Salvador. El incremento de buques y de mercancías en cierto modo sólo fue posible gracias a la construcción del nuevo puerto, pues de otro modo la ciudad de Salvador no habría podido soportar tal flujo de salidas y llegadas al Puerto.

Tabla 1. Movimiento de buques y mercancías. Puerto de Salvador de Bahía, 1950-2000

\begin{tabular}{|c|c|c|c|c|c|c|c|c|c|}
\hline & \multicolumn{2}{|c|}{ Salvador } & \multicolumn{2}{c|}{ Aratu } & \multicolumn{2}{c|}{ Salvador } & \multicolumn{2}{c|}{ Aratu } \\
\hline & Buques & Tm & Buques & Tm & & Buques & Tm & Buques & Tm \\
\hline 1950 & 2341 & 6565000 & - & - & 1980 & 1629 & 2879000 & 884 & 5494000 \\
\hline 1960 & 1444 & 4866000 & - & - & 1990 & 843 & 1438874 & 843 & 1438874 \\
\hline 1970 & 864 & 552249 & - & - & 2000 & 736 & 1992000 & 489 & 18943000 \\
\hline
\end{tabular}

Fuente: Anuário Estatístico do Brasil.

En (https://biblioteca.ibge.gov.br/index.php/biblioteca-catalogo?view=detalhes\&id=720 [consultado 21/3/18])

Este factor ayudó a reducir las tensiones del Puerto de Salvador con su ciudad, especialmente porque se produce una especialización por zonas y se libera suelo para nuevos usos urbanos terciarios. En Salvador quedaron las cargas generales y de movimiento de pasajeros, incluidos los cruceros; mientras en Aratu se localizaron los graneles líquidos (sobre todo petróleo) y los sólidos.

Entre 1970 y 1980 la zona histórica cercana al ámbito portuario de Salvador experimenta una decadencia que supone el traslado del centro de negocios y administrativo de la zona del Pelourinho, Taboão, Praça Municipal y Praça da Sé, hacia la nueva centralidad urbana ubicada en la zona de Iguatemi, Avenida Tancredo Neves y el "Centro Administrativo da Bahia" (CAB), situado en Avenida Paralela.

Asimismo, en la década de 1990, empezó el proceso de restauración de esta área próxima al "Centro Histórico", con desarrollo de la industria turística. Se cambia la función habitacional y de residencia por otra de ocio y servicios turísticos basados en el patrimonio cultural de la ciudad. 
La obsolescencia de la infraestructura portuaria construida a principios del siglo xx se modifica por las mejoras turísticas con empresas especializadas en servicios terciarios. Con todo, esta zona sigue presentando bastantes problemas de tráfico, tanto terrestre como marítimo, esto último debido al escaso calado del puerto. Algunos de estos problemas como el tráfico rodado y la competencia entre el desarrollo urbano de la ciudad y el puerto también se presentarán en Las Palmas de Gran Canaria.

\section{Los procesos de cambio en el puerto de La Luz y Las Palmas}

El puerto de La Luz en la Bahía de La Isleta empieza a fraguarse tras la declaración de Puerto Franco (Decreto del 11 de julio de 1852) y, sobre todo, tras la aprobación en 1881 de una ley estatal que lo clasifica entre los puertos de Refugio, facilitando de esta manera la inversión del Estado en las obras. Estas se realizarían en 1883 según proyecto de Juan de León y Castillo y contarían con un presupuesto inicial de $8.739 .675,70$ pesetas.

En 20 años se construyeron dos diques: el de La Luz (de norte a sur, $1.240 \mathrm{~m}$ ) y el Santa Catalina (de poniente a naciente, $600 \mathrm{~m}$ ). El de La Luz arranca en las inmediaciones del Castillo homónimo, mientras el de Santa Catalina lo hace unos $1.000 \mathrm{~m}$ al sur, y frente al lugar donde más tarde se emplazarían las casas comerciales inglesas de Elder y Miller y el Parque Santa Catalina.

Figura 4. Plano del proyecto del puerto de La Luz y Muelle Santa Catalina (1882)

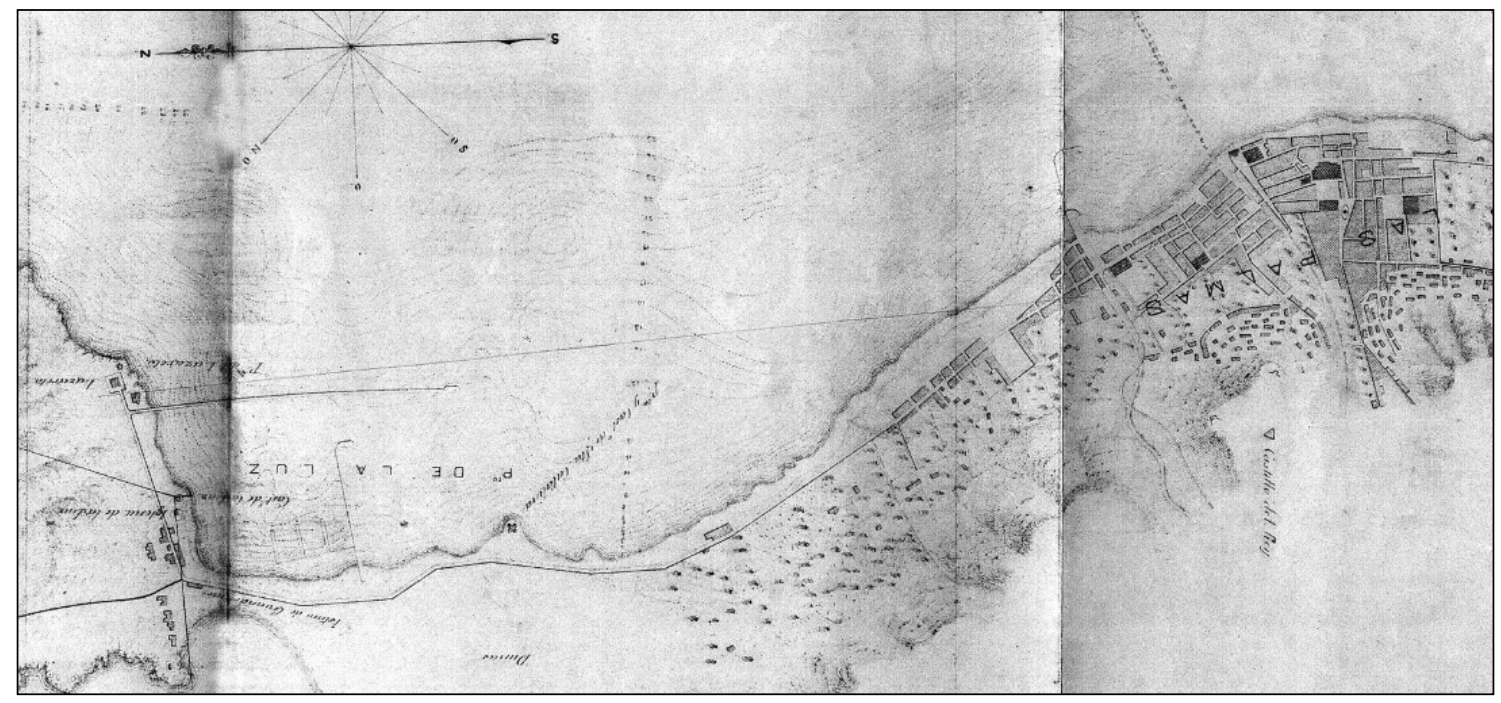

Fuente: Archivo de la Autoridad Portuaria de Las Palmas

La construcción del nuevo muelle de La Luz en La Isleta (figura 4) supondrá el declive definitivo del muelle viejo existente hasta ese momento (Muelle de Las Palmas). Este había sido construido junto a la ciudad decimonónica, en las proximidades del actual Parque de San Telmo, donde a partir del traslado a La Isleta sólo permanecerán algunos carpinteros de ribera. 
El muelle de La Luz, al contrario que el de Las Palmas, tuvo un desarrollo rápido y un gran dinamismo comercial, llegando incluso a suponer una revitalización económica muy importante para la ciudad durante la etapa de construcción. Esta atrajo trabajadores procedentes de otras localidades de Gran Canaria, y también de Lanzarote y Fuerteventura, que se asentaron en terrenos de La Isleta, creando un nuevo núcleo de población, El Puerto, que aparece como entidad independiente en los Nomenclátores de comienzos del siglo xx hasta 1940, cuando es anexado a Las Palmas (Nomenclátores, 1900-1940).

La primera función del puerto fue la de dar abrigo y servicios a los buques de tránsito con mercancías para África y América y permitir la unión con el resto del Archipiélago, sobre todo con la provincia oriental. Desde finales del XIX comenzaron a hacer escala en la isla los trasatlánticos que unían la península con Cuba y Puerto Rico, atracando en la Bahía de La Luz (Cirilo, 2003). De forma paralela continuaron las obras de ampliación del muelle Santa Catalina, desde donde empezaron a operar los correíllos, que unían el puerto de La Luz con los de Puerto del Rosario, en Fuerteventura, y Arrecife, en Lanzarote. En 1903 las obras estaban terminadas y en 1905 se entregaron a la nueva Junta de Obras de los Puertos de La Luz y de Las Palmas.

Con el incremento paulatino de los buques a vapor, el puerto experimentó un notable desarrollo, convirtiéndose en una base de aprovisionamiento de carbón para las flotas inglesas, alemanas y francesas que operaban con África y América. Durante el primer tercio del siglo xx el puerto de la Luz compitió con el de Mindelo en San Vicente (Cabo Verde). Esto supuso que la zona de ribera entre el Castillo de La Luz y el Muelle de Santa Catalina fuera colmatándose con tinglados portuarios y almacenes para guardar el combustible y otros productos con que abastecer las flotas (Cáceres, 2011).

En torno a 1910 ambos diques y los muelles de ribera presentaban un estado de ejecución notable, incluso se había mejorado el suministro de agua a buques y se dragaron determinadas zonas de la bahía (Martín, 2001; Laforet, 2003). La primera conflagración mundial propició un descenso en los tráficos y en las construcciones de infraestructuras (así se recoge en la memoria del Plan General de Servicios del Puerto de 1916). Terminada la contienda empezó el momento álgido de instalación de compañías extranjeras al abrigo del comercio y del carboneo. En la década de 1920 se contaban entre estas empresas: Miller y Cía; The Gran Canary Coaling y Cía; Woermann Linie (alemana); Blandy Brothers y Cía; Cory Brothers; Wilson and Sons y Cía; Compañía Carbonera de Las Palmas, Sociedad Limitada (española) e Hijos de Juan Rodríguez Quegles, entre otras (Archivo de concesiones, Autoridad Portuaria; Herrera, 1984, 2008). Esto supuso la expansión tanto del puerto, como de la ciudad, que comenzó a crecer hacia el norte con los barrios de Arenales, Ciudad Jardín y Alcaravaneras (Delgado, 1992).

En 1914, la Real Orden del 3 de junio reguló el encargo de un nuevo Plan General de Ampliación del Puerto de La Luz, y en 1916 accedió al cargo de ingeniero del puerto Jaime Ramonell Obrador, quien planteó el crecimiento del dique exterior (figura 5) y una vía litoral de servicio junto a la costa para unir Santa Catalina con San Telmo. Esta vía sería crucial para la expansión de la ciudad hacia el norte. 
Figura 5. Estado de las obras del muelle (1925). Ampliación de dique exterior y explanada

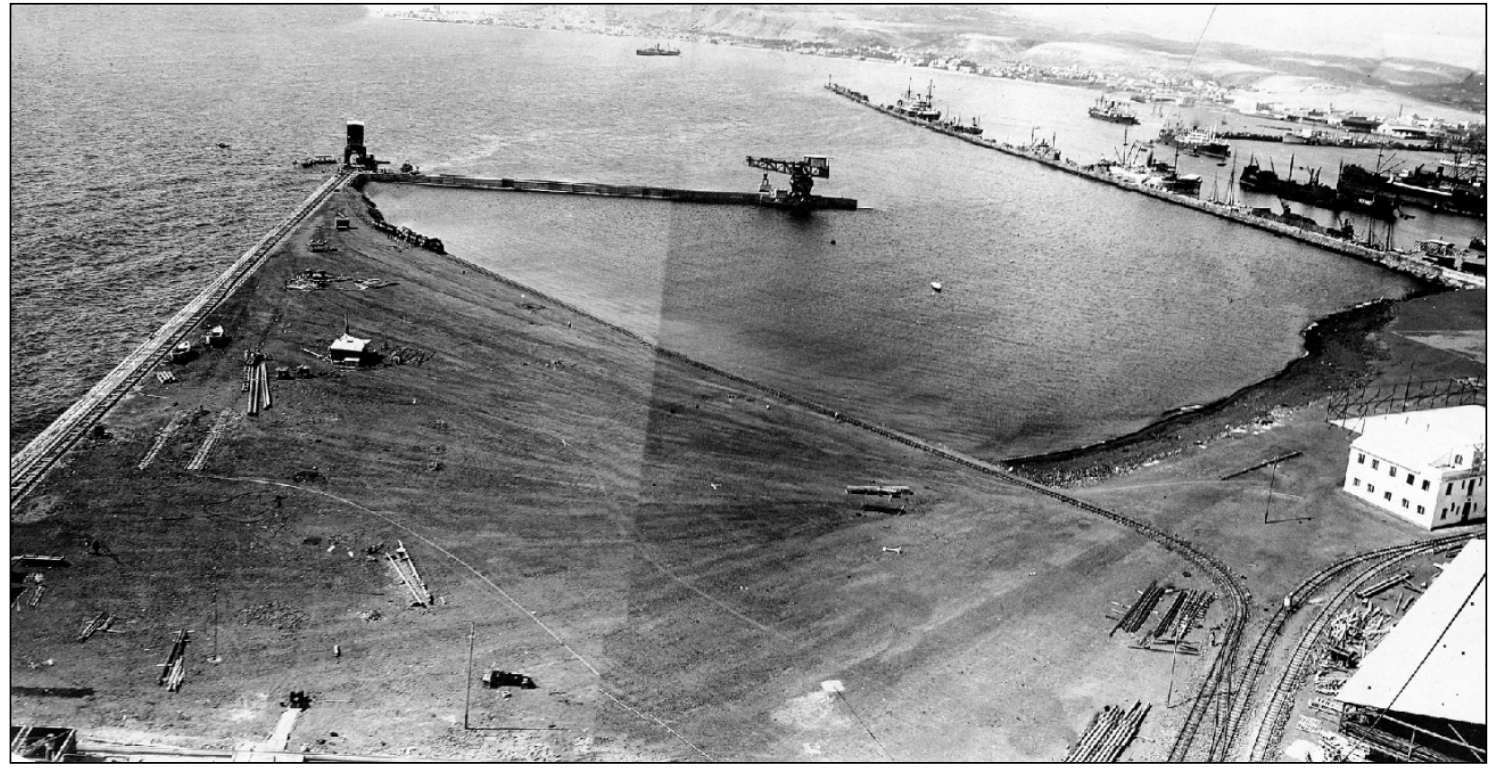

Fuente: Colección privada. Pepe Medina

Tras la Primera Guerra Mundial se inició una etapa de cambios en el muelle de Santa Catalina y el puerto de refugio de La Luz. Se distinguen dos periodos bien distintos: el primero corresponde a los años de entreguerras (1919-1936); mientras el segundo abarca la etapa franquista autárquica (1936-1959) y finaliza con la aprobación del Plan de Estabilización de Ullastres, en este último año. Durante este periodo se redactaron cuatro proyectos de ampliación portuaria (Acedo, Artiles y Rodríguez Rodas, en 1927; Plan Conesa, 1937, Plan Morales, 1947 y Plan Picó, 1954. Ver tabla 2) y, justo al finalizar el periodo, uno más, el Plan General de Ordenación del Puerto de La Luz de Granda Villar de 1960-62. Coincidiendo precisamente con el Plan de Estabilización de Ullastres, a principios de los 60 se redactó el Plan Canarias, germen del futuro puerto del siglo xxI, pues de sus premisas parte la idea de extender el crecimiento portuario hacia las dársenas exteriores, lo que supondrá un enorme salto cualitativo y cuantitativo. Éste se concreta con el Plan General de Ordenación y Obras de los Puertos de La Luz y Las Palmas y anteproyecto de la Dársena Exterior-Primera fase o Plan Vigueras (1964).

De esta manera, en 1927 se aprobó un proyecto reformado de nuevo dique de abrigo para La Luz del ingeniero Rodríguez Rodas. El dique se prolongó hasta los $2.603 \mathrm{~m}$, ganándose una dársena de 180 has y añadiéndose varios muelles de ribera y explanadas. Estas obras las realizó un consorcio formado por dos compañías: la española Compañía Metropolitana de Barcelona S.A. y la holandesa Nederlandsche Matschappy voor Havenwerken (Memoria del Puerto, 1927: 43). Fue una obra muy oportuna para los movimientos de tráfico de pasajeros y mercancías de años posteriores, aunque estos siempre se mostraron con altibajos (tabla 3). El presupuesto ascendió a 38.976.000 de pesetas y las obras finalizaron en 1935, cerrándose así la primera sub-etapa de este periodo. 
Tabla 2. Relación de planes y proyectos portuarios de carácter general (1881-1991)

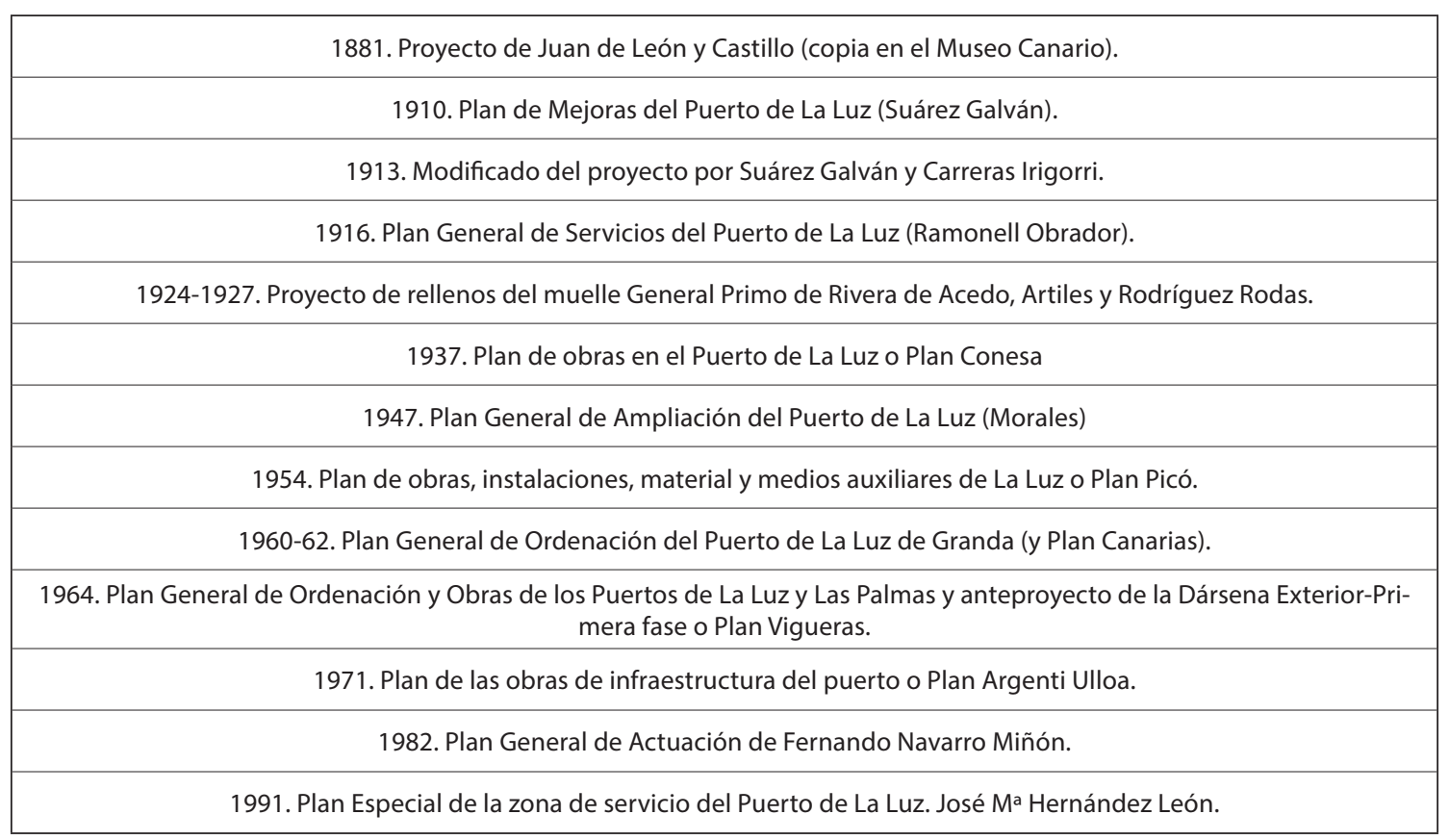

Fuente: elaboración propia a partir del archivo de la Autoridad Portuaria

Tabla 3. Movimiento de buques y mercancías (Tm) en el Puerto de La Luz (1929-1936)

\begin{tabular}{|c|c|c|c|c|c|c|c|}
\hline \multicolumn{2}{|c|}{1929} & \multicolumn{2}{c|}{1930} & \multicolumn{2}{c|}{1931} & \multicolumn{2}{c|}{1932} \\
\hline Buques & Tm & Buques & Tm & Buques & Tm & Buques & Tm \\
\hline 6.070 & 9.095 .728 & 5.890 & 8.433 .234 & 5.986 & 9.422 .708 & 5.804 & 9.492 .674 \\
\hline \multicolumn{2}{|c|}{1933} & \multicolumn{2}{|c|}{1934} & & \multicolumn{2}{|c|}{1935} & 1936 \\
\hline Buques & Tm & Buques & Tm & Buques & Tm & Buques & Tm \\
\hline 5.495 & 8.886 .676 & 5.273 & 8.116 .104 & 5.093 & 8.156 .147 & 4.283 & 6.770 .741 \\
\hline
\end{tabular}

Fuente: Memoria del Puerto de La Luz y de Las Palmas. Años indicados

La construcción del muelle frutero Virgen del Pino, en 1935, representó el inicio de una segunda sub-etapa, que se prolongó hasta 1959 y que supondría la transformación del litoral al sur del muelle Santa Catalina (figura 6). El Plan de obras del puerto de Gregorio Pérez Conesa recoge el proyecto que fue culminado con prontitud, aunque enseguida este nuevo muelle acabó ocupado por el ramo de marina, convirtiéndose en Base Naval en diciembre de $1940^{4}$.

3 Se ha establecido esta fecha por ser un momento en el que la ciudad baja, en contacto con el puerto, se encuentra definitivamente consolidada.

4 OM de 12 de diciembre de 1940.

tiempo\&economía

Vol. 5 N. ${ }^{\circ} 2$ - Julio - Diciembre del 2018

p. 31 
Al finalizar este período se realizó el Plan de Ampliación del puerto del ingeniero Pedro Morales Pleguezuelo, que ensanchaba el muelle de La Luz y recortaba su longitud.

Figura 6. La ciudad y el puerto en 1932, antes de la construcción de la Base Naval

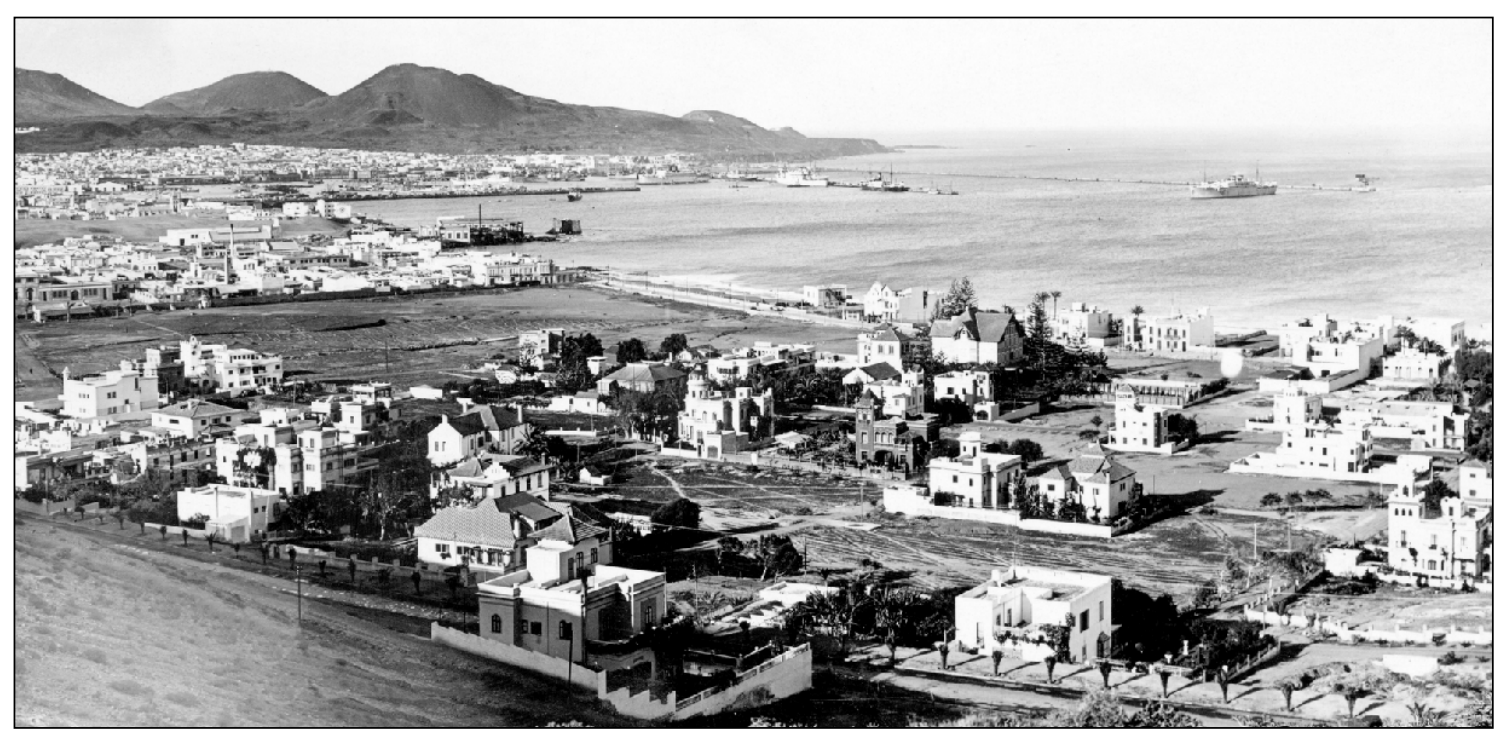

Fuente: Colección privada. Pepe Medina

El cierre del Canal de Suez (Guerra árabe-israelí de 1956), favoreció el tráfico por el Puerto de La Luz, sobre todo de petroleros (Burriel, 1974) lo que supuso que se convirtiera en la gasolinera del Atlántico Medio, suministrando carburante a un tráfico creciente de buques. En esos años, el Puerto de La Luz tuvo que rivalizar con otros como Dakar y, en menor medida, también Santa Cruz de Tenerife, pues otros puertos de la región como Funchal, Casablanca y Mindelo se vieron escasamente favorecidos por esta coyuntura.

Otro factor de gran importancia fue la instalación en la Bahía de La Luz de las flotas pesqueras de Cuba, URSS, Japón, Taiwán, Corea del Sur, China, Malasia y Singapur, que establecieron su base de avituallamiento y arreglos navales. En 1952 se construyó el Muelle Pesquero y los frigoríficos, contribuyendo al desarrollo de esta actividad, que acabaría decayendo en los años 80. Respecto a la ciudad, en la década de 1950 tuvo lugar la construcción de la explanada de Cidemar, ampliación urbana hacia naciente ganando terrenos al mar entre el Parque San Telmo y el Guiniguada, ocupando todo el frente del barrio histórico de Triana. El ayuntamiento gestionó el proyecto a través del arquitecto municipal, Secundino Zuazo, logrando los terrenos en concesión permanente. ${ }^{5}$

En 1966 se comenzó a construir el Dique Reina Sofía, que sufrió varias ampliaciones en años sucesivos, pues el frente marítimo se había colmatado de infraestructuras portuarias, algunas ya obsoletas. Se produjo entonces un cambio de paradigma en cuanto a la planificación puer-

5 Concesión nº 97. Proyecto dique y explanación Cidemar-Ensanche de Triana (autorizado por O.M. de 31 de diciembre de 1951). 
to-ciudad, lográndose desde estos años una mayor integración de ambos espacios. La ciudad en los años sesenta emprende obras de gran envergadura como son la de ganar terreno al mar mediante explanadas hacia naciente (Cidemar, Avenida Marítima. Ver figura 7) y hacia el norte, donde se construyen las instalaciones industriales-comerciales de El Sebadal.

En 1972, mediante un proyecto del ingeniero Juan Argenti Ulloa, se construye la explanada de Astican (Astilleros Canarios) al abrigo del Dique Reina Sofía y de la trasera del muelle León y Castillo, que paulatinamente se irá convirtiendo en el futuro muelle de contenedores y acogerá las actividades industriales y logísticas.

Figura 7. La ciudad y el puerto en las décadas de 1950-60.

Explanadas ganadas al mar por la ciudad y construcción del dique exterior

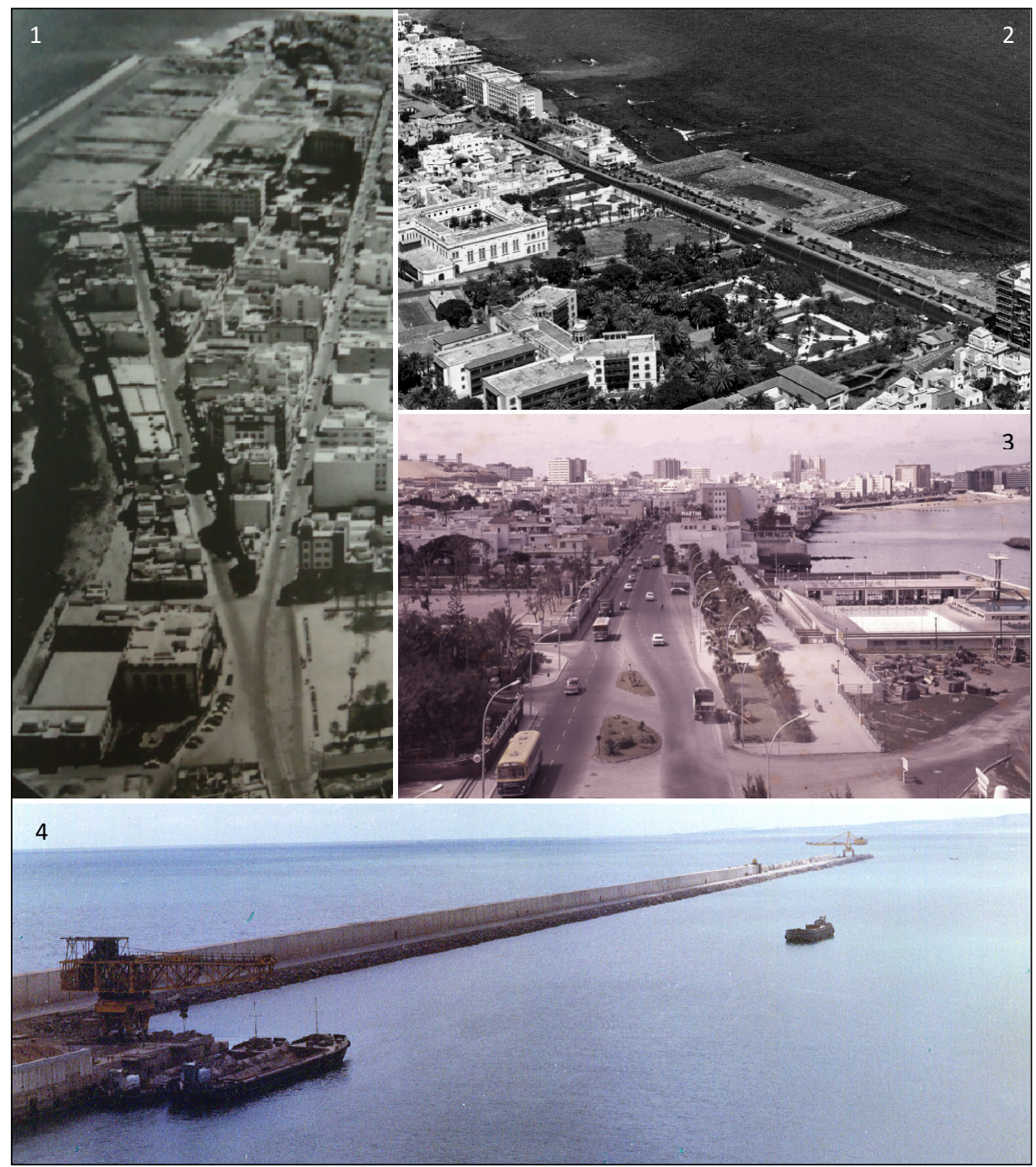

Pie de foto: (1) Explanada de CIDEMAR, espacio urbano ganado al mar en la década de 1950; (2 y 3) Explanada para el Club Natación Metropole (obras, 1965; y recién terminado, 1968); Finalización del dique Reina Sofía (1972).

Fotografías facilitadas por Pepe Medina (Autoridad Portuaria de LPGC)

tiempo\&economía

Vol. 5 N. ${ }^{\circ} 2$ - Julio - Diciembre del 2018

p. 33

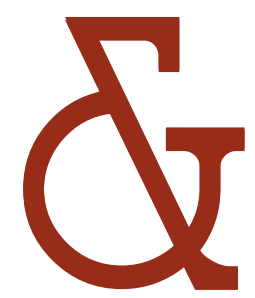


Con el traslado de las actividades más ruidosas y molestas y la construcción en la dársena exterior de Astican se propició que desparecieran los tinglados de Repnaval del entorno del Muelle de Santa Catalina y que esta zona afrontase desde estos años una auténtica transformación. Aquí se instaló el muelle de cruceros y este espacio situado entre la base naval y el Muelle de La Luz está siendo integrado poco a poco en la ciudad mediante diferentes intervenciones: Centro Comercial El Muelle, Parque Islas Canarias, o el más reciente proyecto del acuario Poema del Mar.

Mientras el entorno del viejo muelle Santa Catalina acogía el tráfico de pasajeros y cruceristas, en estos mismos años la trasera del León y Castillo se convierte en muelle de contenedores (una nueva función del puerto), que tras una primera etapa muy competitiva y de rápido crecimiento, entró en crisis entre 2010 y 2015, aunque actualmente está repuntando. Sin embargo, la crisis que no se ha logrado superar ha sido la de la flota pesquera, sobre todo tras la pérdida de la colonia del Sáhara Occidental (1975), estando esta actividad en declive.

Figura 8. Recreación del estado del puerto y la ciudad: 1903, 1940, 1960 y 2000

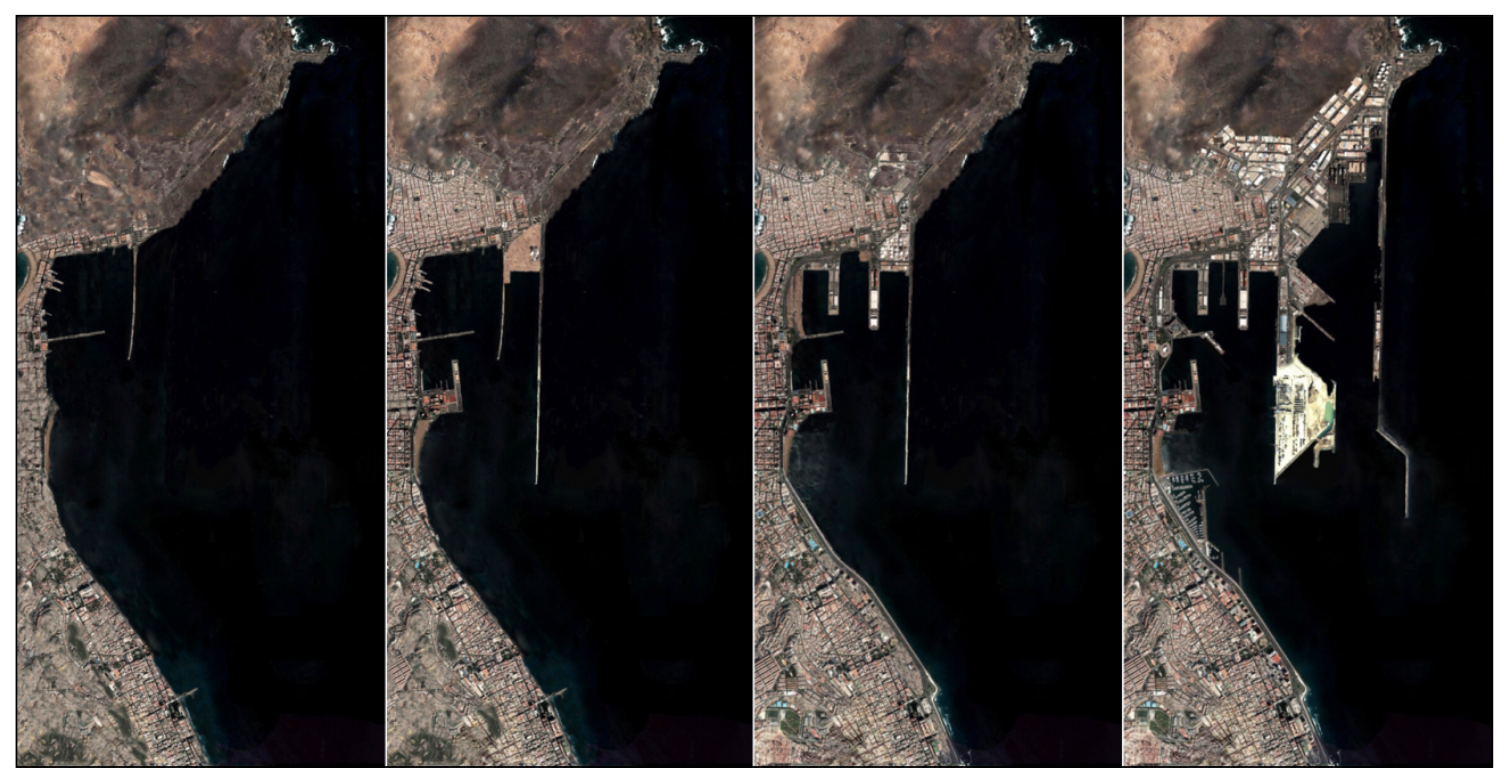

Fuente: Reconstrucción a partir de datos del Archivo de la Autoridad Portuaria de Las Palmas

La incorporación a la Unión Europea en 1986 y la consiguiente pérdida del REF (Régimen Económico y Fiscal, de $1972^{6}$ ) supuso también un varapalo al comercio de bazar (hoy prácticamente desaparecido) y al turismo urbano asociado al puerto de La Luz. En lo que va de siglo el crecimiento del puerto se ha producido hacia naciente, alejado de la ciudad, al tiempo que el tráfico de cruceros ha permitido una cierta reactivación comercial en el entorno próximo a los espacios residenciales. En este sentido, se observa entre los agentes sociales una nueva concepción del litoral urbano, acompañándose esta dinámica de un buen número de ideas y

6 Régimen fiscal diferenciado para Canarias con respecto al resto de España encaminado a promover el desarrollo económico y social del archipiélago. 
proyectos para modificar el frente litoral en contacto con el puerto, tal como podemos ejemplificar por su calado mediático en el proyecto de la Gran Marina (Cáceres y Mirallave, 1996; Delgado, 1998; González y Armengol, 2006). La creación de una comisión Puerto-ciudad, formada por técnicos y responsables de ambas instituciones, ejemplifica el futuro planificado de una manera integral de este espacio de conexión entre el puerto y la trama urbana.

Figura 9. Estado actual del puerto y la ciudad

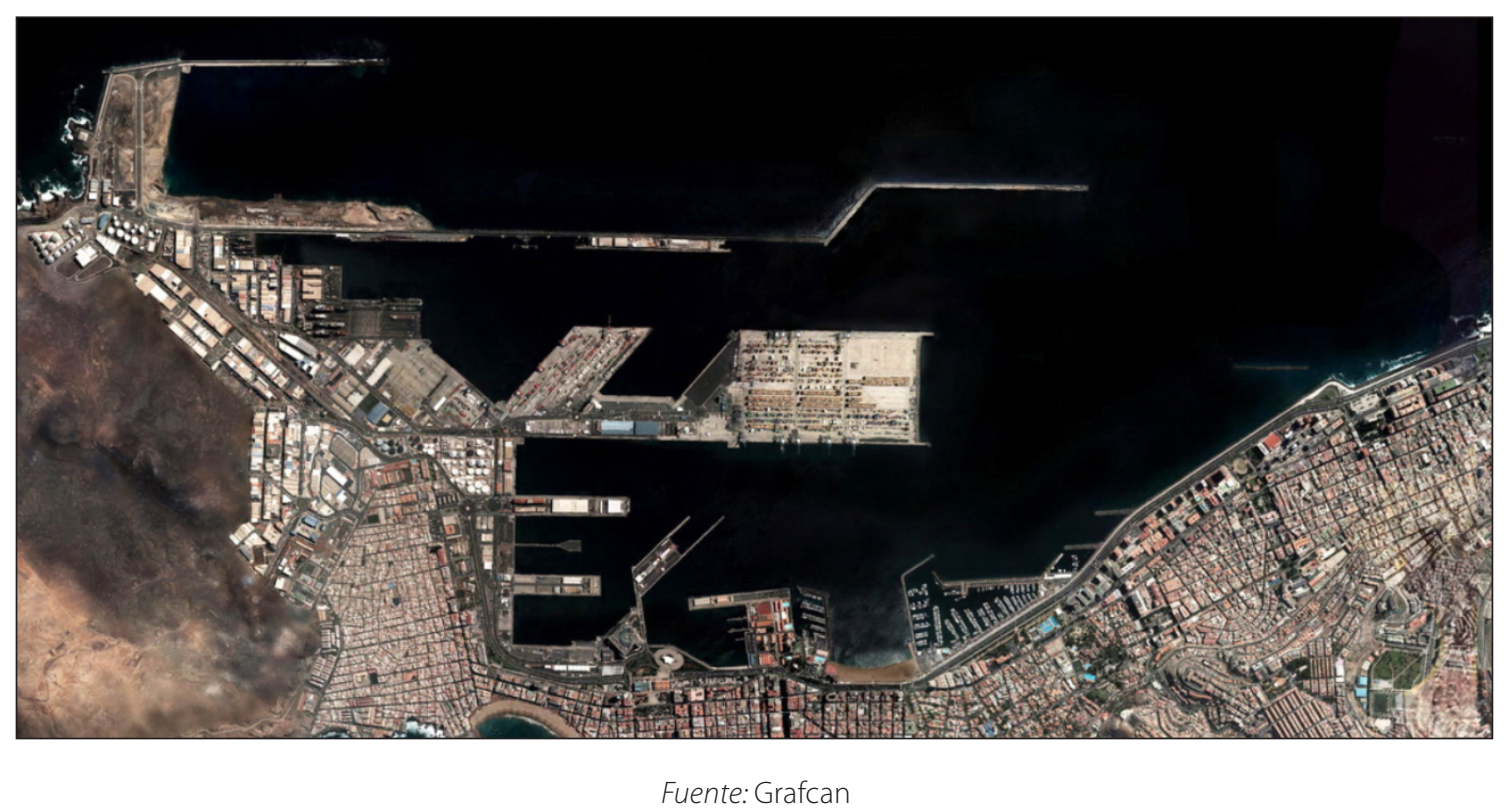

Tras un largo proceso de desarrollo (figuras 8 y 9), asistimos en el siglo xxI a una nueva etapa en el crecimiento portuario, con una diversificación de funciones y una planificación orientada a alejar de la ciudad aquellas actividades que resultan más molestas, mientras que el frente marítimo portuario histórico experimenta una transformación profunda y pasa a integrarse con la ciudad, acogiendo actividades del sector terciario y convirtiéndose en espacio de ocio urbano y turístico.

\section{Conclusiones}

En el proceso de cambio de los puertos de La Luz y de Las Palmas, en Gran Canaria, y de Salvador de Bahía y Aratu, en Brasil, hay notables diferencias, tanto en lo concerniente al espacio físico como a las dimensiones superficiales de los espacios objetos de estudios. Las dos ciudades presentan como rasgo más característico y común una parte baja y otra alta, donde la evolución hacia la terciarización es el aspecto más destacado de ambas urbes. Asimismo, son importantes las diferencias entre ambos espacios en las diferentes etapas por las que han pasado estos puertos, pero también hay similitudes dignas de mención. En efecto, las etapas de los puertos brasileños y grancanario son fundamentalmente tres: antes de finales del siglo XIX y comienzos del $x x$, en el que el puerto de Salvador se especializa en el comercio de esclavos y en las mercancías coloniales, sobre todo la caña de azúcar. En este mismo periodo en el puerto grancanario, esto es el de Las Palmas, pues el de La Luz se crea a finales del XIX, también hay 
un comercio de productos de exportación entre ellos la caña de azúcar, sin embargo el tráfico de esclavos no fue tan importante en relación a otros espacios geográficos del Atlántico. En ambos casos la ciudad y el puerto presentan crecimientos paralelos donde se ocupa la ribera marítima con el espacio portuario y la ciudad crece en su parte baja, para el caso grancanario; mientras en Salvador también el desarrollo urbano será homogéneo en ambas zonas, esto es en la parte alta y baja de la ciudad.

Una segunda etapa se produce a partir del siglo XIX y llega hasta mediados del siglo xx. En esta fase el puerto de Salvador de Bahía y el de La Luz experimentan una evolución también diferenciada, en el primer caso con motivo de la importancia que cobra Santos, Río de Janeiro y Pernambuco, el puerto de Salvador entra en una fase regresiva y las obras de modernización se ralentizan; por su parte el de La Luz, al abrigo del carbón experimentará un gran auge y más tarde también seguirá creciendo con la introducción de los combustibles fósiles. El dinamismo de la luz en esta etapa también está motivado por la pesca. En una primera sub-fase (19191936) de esta etapa, el crecimiento será escaso por las coyunturas económicas y sociopolíticas adversas. En la segunda sub-fase (1936-1959), sobre todo tras la segunda guerra mundial se producirá el mayor crecimiento de esta etapa, al finalizar la cual la parte baja de la ciudad queda prácticamente colmatada, y comenzará el crecimiento de los barrios de la Ciudad Alta. En cambio en Salvador ambos crecimientos (Ciudad Alta y Ciudad Baja) se dieron de forma paralela. Se ponen también los cimientos para la expansión de la ciudad ganando terreno al mar, aspecto de similar característica ocurre en Salvador de Bahía, donde se produce un ensanchamiento de la parta baja gracias a la expansión del frente marítimo.

Entre mediados del siglo xx y la actualidad se produce una evolución similar en ambos espacios, pues el puerto de Brasil incrementa el comercio de graneles y sobre todo de petróleo, con el un nuevo puerto (Aratu) que se construye lejos de la ciudad y se conecta con esta mediante autopista. En cambio, en La Luz se sigue construyendo infraestructura portuaria cerca de la ciudad, aunque ahora en una dársena exterior, es decir en ambas zonas crece el espacio portuario, aunque con estrategias distintas, pues en un lado se hace con infraestructuras lejos de la ciudad, mientras en el otro se sigue ganando terreno portuario en un avance hacia el norte que supone la ocupación de parte de La Isleta y de muelles de mayor calado y dimensiones (Reina Sofía y Nelson Mandela). Ahora la pesca entra en declive en La Luz, pero las reparaciones navales experimentan un gran auge. Esto permite en ambos casos liberar espacio portuario obsoleto para reconvertirlo en áreas urbanas más dinámicas, asociadas al ocio, al turismo, sobre todo de cruceros, y a nuevas funciones de terciarización. Este último proceso se da de forma análoga en ambos espacios objetos de estudio, es decir unos puertos con mayor especialización y una ciudad donde las actividades del sector terciario asociadas al ocio ganan presencia e importancia, por ejemplo la zona del Pelouriño en Salvador, o la zona próxima al parque de Santa Catalina en Las Palmas de Gran Canaria.

\section{Referencias}

Burriel de Orueta, E. (1974). El puerto de la Luz en Las Palmas de Gran Canaria. CIES, 18. Las Palmas de Gran Canaria.

Cáceres M., E. y Mirallave I., V. (1996). La reutilización de los espacios portuarios obsoletos. En Las Palmas: ciudad-puerto (pp. 63-72). Las Palmas de Gran Canaria. 
Cáceres M., E. (2011). La formación urbana de Las Palmas. Materiales de trabajo, 5. Escuela Técnica Superior de Arquitectura de Las Palmas.

Casariego, J., Guerra, E., Ley P. y Palop, J. (1999). Waterfronts de nuevo. Transformaciones en los frentes urbanos de agua. Las Palmas de Gran Canaria: Ayuntamiento de Las Palmas de Gran Canaria.

Cirilo M., J. (2003). De los puertos de La Luz y de Las Palmas y otras historias. Las Palmas de Gran Canaria: Estudio preliminar de Simón Benítez Padilla. Gabinete Literario. Recuperado en Memoria digital de Canarias.

Delgado A., G. (1992). Transporte y comunicaciones marítimas en Gran Canaria. Las Palmas de Gran Canaria: CIES.

Delgado A., G. (1998). Las relaciones puerto-ciudad en Las Palmas de Gran Canaria: tensiones y tendencias territoriales. Vegueta, 3, 243-254.

Delgado A., G., González M., A., Hernández L., J. y Sigut M., V. (2007). Puertos y sistemas portuarios de las Islas atlánticas europeas (Canarias, Azores y Madeira). Santa Cruz de Tenerife: Ediciones Idea.

Gómez O., J. L. y Grindlay M., A. (1998). Problemas medioambientales en las ciudades marítimas: la relación ciudad-puerto. I Congreso Mundial Salud y Medio Ambiente Urbano. Madrid.

González L., N. (2001). Mercantilismo, ciencia y viajeros ingleses en Canarias durante la época estuardiana. En A. Bethencourt (coord.), Coloquio Internacional de Canarias y el Atlántico, 1580-1648. IV Centenario del ataque de Van der Does a las Palmas de Gran Canaria, 1999 (pp. 795-820). Cabildo de Gran Canaria. Las Palmas de Gran Canaria.

González M., A. y Armengol M., M. (2006). El Istmo de Santa Catalina en Las Palmas de Gran Canaria: un espacio singular con un controvertido proyecto urbanístico. Vegueta, 9, 175-192.

González, A. y Ramón, A. (2016). Transformaciones en el muelle de Santa Catalina del Puerto de La Luz y Las Palmas y su adaptación al turismo de cruceros (1952 -2016). IV Coloquio Internacional de la Gobernanza de los Puertos Atlánticos. Lorient, Francia.

Hayuth, Y. (1989). Editor's introduction: the dynamics and dimensions of port-City interrelationships. Geoforum, 20(4), 427. DOI: https://doi.org/10.1016/0016-7185(89)90025-0

Herrera P., A. (1984). Las Palmas de Gran Canaria (2a ed.). Madrid: Edit. Rueda.

Herrera P., A. (2008). El puerto de la Luz, textos para una exposición conmemorativa. En 125 años de Nuestro Puerto. Una historia unida al desarrollo de la ciudad (pp. 14-64). Las Palmas de Gran Canaria: Autoridad Portuaria de Las Palmas.

Honorato, C. (1983). O polvo e o porto: a Cia. Docas de Santos. Santos, São Paulo: HUCITEC. Prefeitura Municipal de Santos.

Honorato, C. y Mantuano, T. (2015). O que era o trapiche? O porto e a cidade do Rio de Janeiro no século XIX. Acervo. Revista do Arquivo Nacional, 28(1), 144 - 158 
Hoyle, B. S., (1994). "Development dynamics at the port-city interface”, en Hoyle, B. S.; Pinder, D. A., y Husain, M. S., Revitalising the waterfront. International dimension of dockland redevelopment, Chichester: John Wiley \& Sons.

Hoyle, B. S. (1997/98). Cities and Ports: Concepts and issues. Vegueta, 3, 263-278.

Laforet, J. J. (2003). El puerto de La Luz en Las Palmas de Gran Canaria. Las Palmas de Gran Canaria: Caja Rural de Canarias.

Lapa, A. (1968). A Bahia e a Carreira da India. São Paulo: Companhia Editora Nacional.

Lobo Cabrera, M. (1993). El comercio del vino entre Gran Canaria y las Indias en el siglo XVI. Las Palmas de Gran Canaria: Ediciones del Cabildo Insular de Gran Canaria.

Martín G., F. (2001). La formación de Las Palmas: ciudad y puerto. Cinco siglos de evolución histórica. Las Palmas de Gran Canaria: Fundación Puertos de Las Palmas.

Medina S., J. (1996). Isleta / Puerto de La Luz: Raíces. Autoedición. Las Palmas de Gran Canaria.

Moreno P., J. (2015). Açambarcadores e famélicos; fome, carestia e conflitos em Salvador, 18581878. Rio de Janeiro: Tese de Doutorado. PPGH/UFF.

Ramón O., A. y González M., A. (2017). La planificación del espacio portuario de Gran Canaria en sus primeras etapas de desarrollo, 1883-1990. VI Coloquio Internacional de la Gobernanza de los Puertos Atlánticos. Puertos y desarrollo. Las Palmas de Gran Canaria.

Rosado, R. (1983). O Porto de Salvador: modernização em Projeto, 1854/1891. Salvador. Brasil: Dissertação de Mestrado, PPGH/UFBA.

Rosado, R. (2000). Cronologia Portos da Bahia. Salvador. Brasil, 2ª ed. Centro de Documentação, CODEBA.

Rowe, P. et al. (2001). Área de oportunidad: Renovación del Frente Marítimo de Las Palmas de Gran Canaria, España. Cambridge, Mass.: Harvard University. Graduate School of Design. Department of Urbana Planning and Design.

Santos, F. G. (2013). Economia e cultura do Candomblé na Bahia: o comércio de objetos litúrgicos afro-brasileiros, 1850/1937. Ilhéus, Bahia: Editus editora da Universidade estatal de Santa Cruz.

Santos, F. G. (2015). Saiam as carroças, entre o progresso! Em: D. do Carmo Kabengele \& A. P. Palamartchuk (Orgs.), Diálogos possíveis: a cultura nas ciências humanas (pp. 161-186). Maceió: Editora da Universidade Federal de Alagoas.

Sampaio, L. (1928). Indicador e Guia Prático da Cidade de Salvador. Salvador: Tipografia Barbosa \& Cia.

Suárez B., M. (2000). El tráfico de mercancías por el puerto de La Luz y de Las Palmas. XIII Coloquio de Historia Canario-americana (pp. 2175-2188). Cabildo de Gran Canaria. Las Palmas de Gran Canaria.

Tous M., J. y Herrera P., A. (1995). Las Palmas de Gran Canaria a través de la cartografía, 15881899. Casa de Colón y Museo Militar Regional de Canarias. 
Anexo. Tabla comparativa de la evolución urbano-portuaria de Las Palmas de Gran Canaria y Salvador de Bahía (siglos XV-XXI)

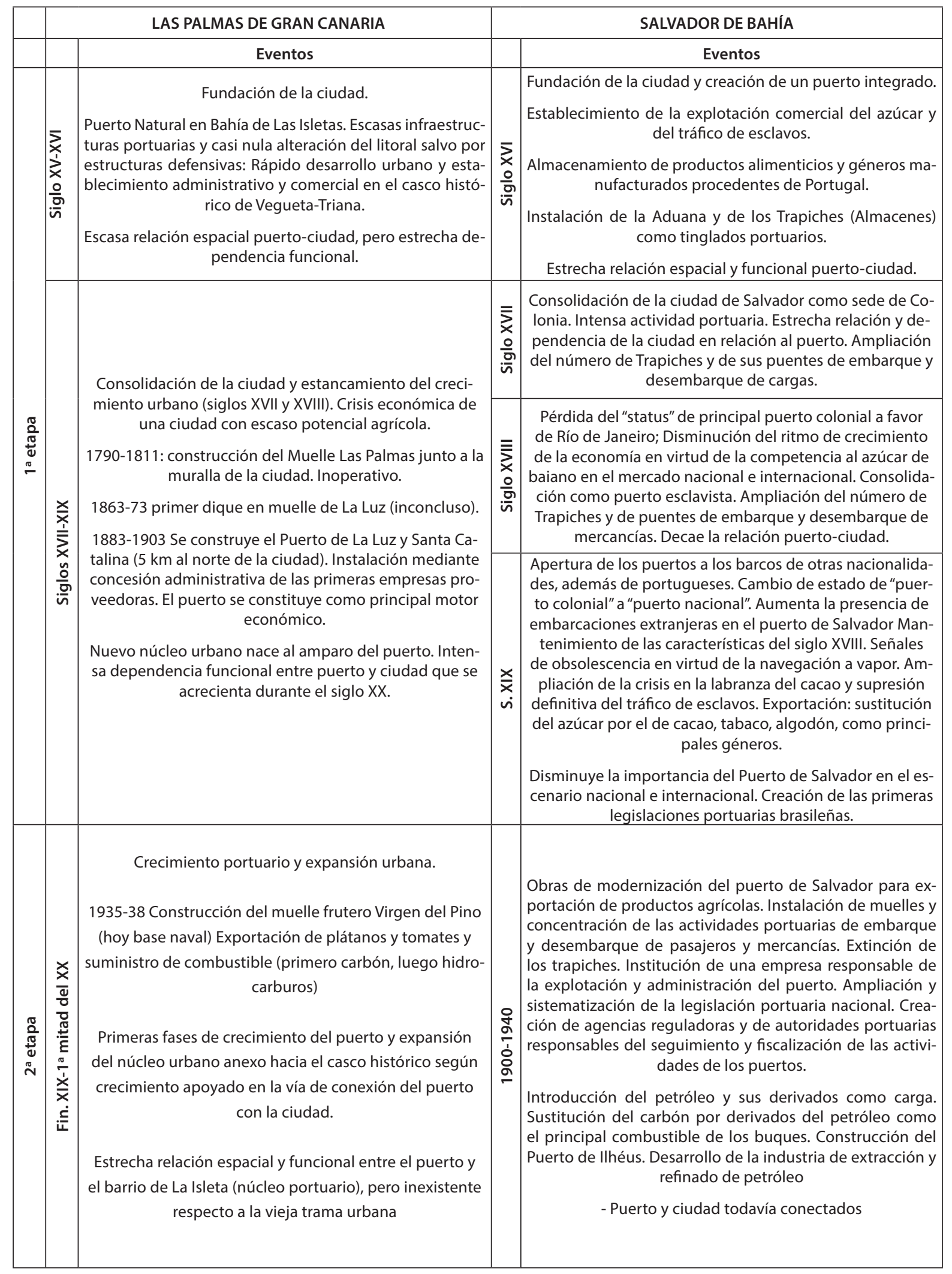

Vol. 5 N. ${ }^{\circ} 2$ - Julio - Diciembre del 2018 


\begin{tabular}{|c|c|c|c|c|}
\hline & & LAS PALMAS DE GRAN CANARIA & & SALVADOR DE BAHÍA \\
\hline & & Eventos & & Eventos \\
\hline 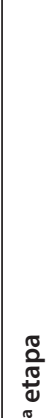 & 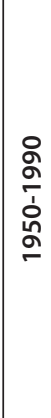 & $\begin{array}{l}\text { Aprobación y ejecución de los planes de crecimiento del } \\
\text { puerto. Se construyen las dársenas exteriores. Construc- } \\
\text { ción a naciente de los diques Reina Sofía y Nelson Mande- } \\
\text { la. Urbanización industrial El Sebadal (La Isleta). } \\
\text { Especialización por zonas o desdoblamiento de las in- } \\
\text { fraestructuras portuarias. } \\
\begin{array}{l}\text { El puerto se aleja de la ciudad (contenerización y otras ac- } \\
\text { tividades industriales se trasladan hacia La Isleta, aleján- } \\
\text { dose de la ciudad). }\end{array}\end{array}$ & 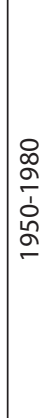 & $\begin{array}{l}\text { Industrialización de Bahía; desarrollo de la extracción y y } \\
\text { refinado de petróleo; implantación del Centro Industrial } \\
\text { de Aratu y del Polo Petroquímico de Camacari y parques } \\
\text { industriales automovilísticos y otros. Construcción y am } \\
\text { pliación del Puerto de Aratu. Construcción del Puerto de } \\
\text { Malhado (Ilhéus). Creación de autoridades portuarias (na- } \\
\text { cional y regional). Especialización de los puertos bahianos, } \\
\text { según la vocación de las áreas donde están instalados. } \\
\text { Ampliación y modernización del Puerto de Salvador. }\end{array}$ \\
\hline & $\frac{\hat{\sigma}}{\frac{1}{1}}$ & $\begin{array}{l}\text { Transformación de infraestructuras portuarias obsole- } \\
\text { tas. Terciarización. Terminal de cruceros, Centro Co- } \\
\text { mercial el Muelle, Espacios libres y de ocio (Museo de } \\
\text { la Ciencia) y Acuario. } \\
\begin{array}{c}\text { Reconversión del waterfront. Mayor integración entre } \\
\text { frente litoral y ciudad. }\end{array}\end{array}$ & 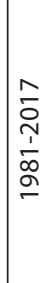 & $\begin{array}{l}\text { Reformulación de la legislación portuaria. Extinción de la } \\
\text { autoridad portuaria nacional. Reglamentación y amplia- } \\
\text { ción del número de terminales portuarias de uso privado } \\
\text { Estructuración y ampliación de las actividades de cruceros } \\
\text { marítimos y recalificación de áreas en el entorno del puer- } \\
\text { to, volcadas al ocio y al turismo. Terciarización }\end{array}$ \\
\hline
\end{tabular}

